\title{
Microplastics in mangroves and coral reef ecosystems: a review
}

\author{
Juliana John $^{1}$ - A R Nandhini ${ }^{2}$ · Padmanaban Velayudhaperumal Chellam ${ }^{3}$ (D) Mika Sillanpääa,5,6,7
}

Received: 26 August 2021 / Accepted: 8 September 2021 / Published online: 7 October 2021

(c) The Author(s), under exclusive licence to Springer Nature Switzerland AG 2021

\begin{abstract}
Microplastic pollution has recently been identified as a major issue for the health of ecosystems. Microplastics have typically sizes of less than $5 \mathrm{~mm}$ and occur in various forms, such as pellets, fibres, fragments, films, and granules. Mangroves and coral reefs are sensitive and restricted ecosystems that provide free ecological services such as coastal protection, maintaining natural cycles, hotspots of biodiversity and economically valuable goods. However, urbanization and industrial activities have started contaminating even these preserved ecosystems. Here we review sources, occurrence, and toxicity of microplastics in the trophic levels of mangrove and coral reef ecosystems. We present detection methods, such as microscopic identification and spectroscopy. We discuss mitigating measures that prevent the entry of microplastics into the marine environment.
\end{abstract}

Keywords Microplastics $\cdot$ Ecosystems $\cdot$ Mangroves $\cdot$ Coral reefs $\cdot$ Pollution $\cdot$ Toxicity

$\begin{array}{ll}\text { Abbreviations } \\ \text { AcHE } & \text { Acetyl cHoline Esterase } \\ \text { ATR } & \text { Attenuated Total Reflection } \\ \mathrm{BaP} & \text { Biofilm-associated Protein } \\ \mathrm{BP} 3 & \text { Binding Protein 3 } \\ \text { casp3b } & \text { Caspase 3 protein } \\ \mathrm{CO}_{2} & \text { Carbon dioxide } \\ \mathrm{COVID}-19 & \text { Corona Virus Disease 2019 } \\ \text { DOE } & \text { Diffractive Optical Element } \\ \text { EDX } & \text { Energy Dispersive X-ray spectroscopy }\end{array}$

Padmanaban Velayudhaperumal Chellam vcpadmanaban88@gmail.com

1 Department of Civil Engineering, National Institute of Technology, Tiruchchirappalli, India

2 Environmental Science and Technology, Anna University, Chennai, India

3 Centre for Research, Department of Biotechnology, Kamaraj College of Engineering and Technology, Madurai, India

4 Chemistry Department, College of Science, King Saud University, Riyadh 11451, Saudi Arabia

5 Faculty of Science and Technology, School of Applied Physics, University Kebangsaan Malaysia, 43600 Bangi, Selangor, Malaysia

6 International Research Centre of Nanotechnology for Himalayan Sustainability (IRCNHS), Shoolini University, Solan, Himachal Pradesh 173212, India

7 School of Chemical and Metallurgical Engineering, University of the Witwatersrand, 2050 Johannesburg, South Africa

\begin{tabular}{|c|c|}
\hline FESEM & $\begin{array}{l}\text { Field Emission Scanning Electron } \\
\text { Microscopy }\end{array}$ \\
\hline FTIR & Fourier Transform Infrared \\
\hline $\operatorname{gadd} 45 \mathrm{ba}$ & $\begin{array}{l}\text { Growth arrest and DNA-damage inducible, } \\
\text { beta protein }\end{array}$ \\
\hline GC-MS & Gas Chromatography-Mass Spectroscopy \\
\hline $\mathrm{H}_{2} \mathrm{O}_{2}$ & Hydrogen peroxide \\
\hline $\mathrm{Km}^{2}$ & Square kilometre \\
\hline $\mathrm{KOH}$ & Potassium hydroxide \\
\hline LASER & $\begin{array}{l}\text { Light Amplification by Stimulated Emission } \\
\text { of Radiation }\end{array}$ \\
\hline LDPE & Low density polyethylene \\
\hline $\mathrm{m}^{3}$ & Cubic metre \\
\hline $\mathrm{mm}$ & Milli metre \\
\hline$\mu g \mathrm{~L}^{-1}$ & Microgram per litre \\
\hline MPs & Micro Plastics \\
\hline MT & Metric Tonnes \\
\hline NOAA & $\begin{array}{l}\text { National Oceanic and Atmospheric } \\
\text { Administration }\end{array}$ \\
\hline $\mathrm{p} 53$ & Protein 53 \\
\hline PBS & Polybutylene succinate \\
\hline $\mathrm{PE}$ & Polyethylene \\
\hline PET & Polyethylene terephthalate \\
\hline PHA & Poly hydroxy alkanoate \\
\hline PLA & Polylactic acid \\
\hline $\mathrm{PP}$ & Polypropylene \\
\hline PPCPs & Personal care products \\
\hline PPE & Polypropylene ether \\
\hline PS & Polyester \\
\hline
\end{tabular}




$\begin{array}{ll}\text { ptgs2a } & \text { Prostaglandin-endoperoxide synthase } 2 \\ \text { PVC } & \text { Polyvinyl Chloride } \\ \text { REDOX } & \text { Oxidation-reduction } \\ \text { ROS } & \text { Reactive Oxygen Species } \\ \text { SDG } & \text { Sustainability Development Goals } \\ \text { SEM } & \text { Scanning Electron Microscopy } \\ \text { TEM } & \text { Transmission Electron Microscopy } \\ \text { tnfa } & \text { Tumour Necrosis Factor alpha } \\ \text { UV } & \text { Ultraviolet } \\ \text { w/w } & \text { Weight by weight }\end{array}$

\section{Introduction}

The marine ecosystem is a huge body of saltwater covering the surface of the earth, and it provides the home for significant biodiversity along with assisting roughly half of the global primary production (Alimba and Faggio 2019). Marine ecosystems contribute a plethora of ecosystem services, such as food, carbon sink, waste detoxification, recreational opportunities, and spiritual enhancement. Small and Nicholls (2003) had reported that about $23 \%$ of the world's population (1.2 billion people) live within $100 \mathrm{~km}$ of the coast. Any abrupt decline in providing crucial ecosystem services, will ultimately lead to loss of food security, sustenance, income and health, thereby affecting the wellbeing of humans (Alimba and Faggio 2019), (Beaumont et al. 2019). Rapid exponential population explosion enhanced human activities, such as industrial, agricultural, medical requirements and municipalities, and are being responsible for the increase in marine and terrestrial pollution across the world, by generating thousands of xenobiotics due to inefficient management (Alimba and Faggio 2019).
The marine ecosystem is threatened by various factors, such as accumulation of anthropogenic debris, overexploitation and harvesting of marine resources, disposing wastes, intrusion of alien species, land reclamation activities, dredging and global climate change (José 2002). The accumulation of these debris in the environment is regarded as a huge problem, gaining international attention, because of the growing production of plastics (Van Cauwenberghe et al. 2013). Global plastic production has increased from 250 million metric tonnes (MT) in 2009, to 368 million metric tonnes in 2019. Jambeck et al. (2017) had reported that as of 2015, 6300 MT of cumulative primary and secondary (recycled) plastic waste had been generated (Jambeck et al. 2017). If the current global waste management trends and increase in production continues, by 2050, 12,000 MT of plastic waste will be incinerated, 9000 MT will be recycled, and 12,000 MT of waste will be disposed of in landfills or in the natural environment.

The oceans remain as the destination for many plastic items and macroplastic debris greater than 5 milli metre in diameter, and acts as a dump for the xenobiotics (Fendall and Sewell 2009; Alimba and Faggio 2019; Huang et al. 2021) Globally, 10 major rivers carry most of the plastic wastes to the oceans, and contributes to about $90 \%$ of the ocean plastic pollution (Schmidt et al. 2017). The amount of plastic wastes that ends up within oceans by each river is shown in Fig. 1.

However, this alarming prediction of plastic pollution in the marine environment by (Carpenter et al. 1972) caught nominal scientific attention. Four decades (40 years) since the report, the topic gained substantial interest with supporting data on their impact on the marine ecosystem, and it became a global environmental concern and a serious public health issue (Andrady 2011; Alimba and Faggio 2019). In
Fig. 1 A representation of major rivers that are contributing to plastic wastes (in tons) into marine environment

\section{Major rivers contributing to plastic pollution in oceans}

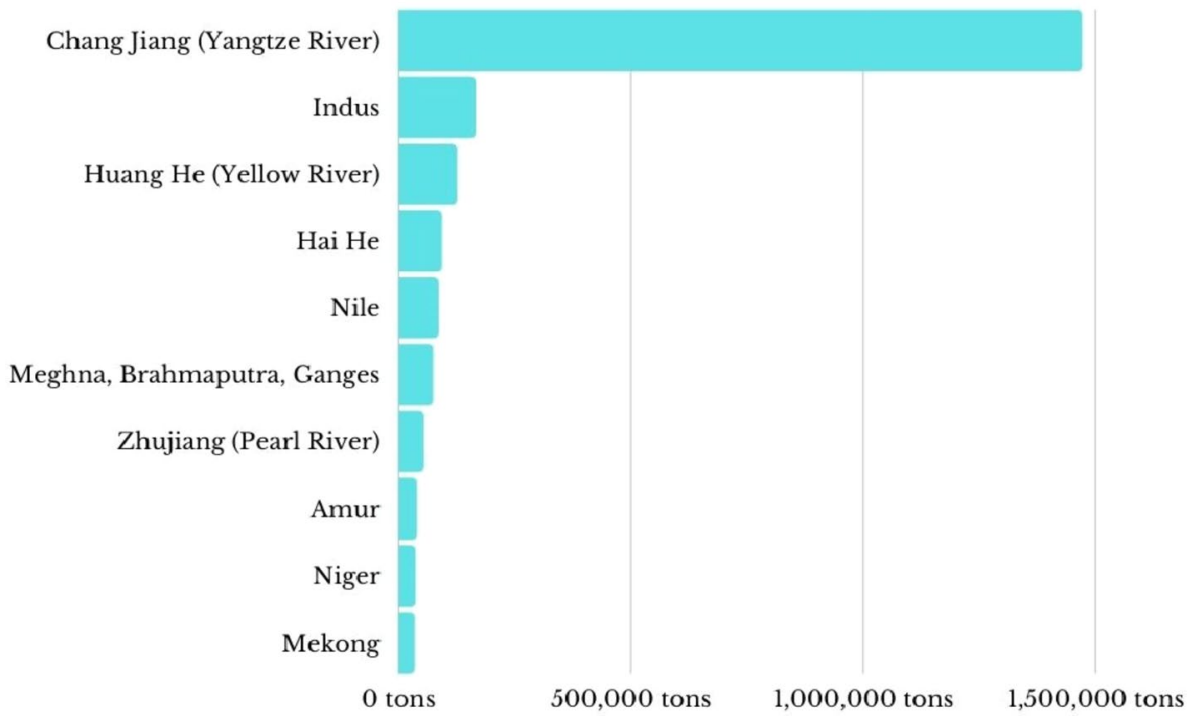


1972, Carpenter and Smith were the first to report the plastic debris in the ocean, when they were sampling the pelagic Sargassum community in the western Sargasso Sea. They observed that the source of the debris may be due to dumping of waste from cities, or by maritime transport. They stated in their report, "Pieces are brittle, apparently due to the weathering of the plasticizers, and many are in a pellet shape about $0.25-0.5 \mathrm{~cm}$ in diameter. The particles are surfaces for the attachment of diatoms and hydroids. Increasing production of plastics, combined with present waste-disposal practices, will undoubtedly lead to increases in the concentration of these particles" (Carpenter et al. 1972; Ivar Do Sul and Costa 2014). In 2004, Thompson (2004) along with his collaborators were the first researchers to coin the term "microplastics" (MPs) in their paper, "Lost at sea: Where is all the plastic?". Microplastics are defined as fragments smaller than 5 milli meter in diameter by the National Oceanic and Atmospheric Administration (NOAA) (Barboza and Gimenez 2015). These microplastics enter the marine environment from land through wastewater systems (Fendall and Sewell 2009; Ivar Do Sul and Costa 2014; Barboza and Gimenez 2015; Sevwandi Dharmadasa et al. 2021).

The tropical seascape of a marine ecosystem comprises of three important habitats, mangroves, coral reefs, and seagrass meadows (Guannel et al. 2016). The symbiotic relationship between mangroves and coral reef ecosystems contributes to natural barrier forming abilities against natural destructions. Being a unique wetland, it is distinguished by sediments, recurrent flooding and long-term relationship with terrestrial and marine ecosystems (Zhang et al. 2020). Despite this huge importance, mangrove ecosystems are vulnerable and threatened by various pollutants. The majority of the debris polluting the mangroves, are plastics, textiles, glass, wood, etc. Plastics constitutes for about $70 \%$ of the total marine debris, concerning the mangroves (Deng et al. 2021). Marine litters are brought to mangrove ecosystems by waves and surface currents (Deng et al. 2021). The trapped plastic by mangroves hinders the tree and surrounding fauna, by inhibiting gas exchange, and releasing harmful chemicals (Martin et al. 2019).

Coral reefs are an irreplaceable and indispensable environmental and economic treasure. Being one of the richest marine habitat, it provides livelihood for more than 275 million people (Cordova et al. 2018; Huang et al. 2021). Yet, it has been constantly threatened by anthropogenic activities, such as overfishing, coastal development, global warming, climate change and ocean acidification. Microplastics, an emerging pollutant, has been a rising concern among many pollutants, because they are ubiquitous and increased susceptibility to diseases (Reichert et al. 2019; Tan et al. 2020). Corals can deal with microplastics by ingesting and partially egesting or by cleaning mechanisms, such as mucus release, that can be energy intensive, and can potentially interfere with the normal functioning heterotrophic feeding, ultimately impacting the growth. In addition, it causes pathogen transmission through particle-associated microbial biofilms, necrosis and bleaching on coral reefs, increasing their disease risk to about 85\% (Lamb et al. 2018; Reichert et al. 2018, 2019; Tan et al. 2020). Thus, plastics inhibits coral development, posing a significant threat, and imperils the cold-water coral reefs resilience and their biodiversity (Chapron et al. 2018).

This review provides a detailed overview of microplastics and their toxicological impacts in environment. Being sensitive ecosystems, the components of mangroves and coral reefs, their ecological importance, and the extent of ecological health affected due to entry of microplastics within these ecosystems, have been explained in detail. A brief explanation on the advancements in detection techniques from visual identification till advanced microscopic coupled spectroscopic techniques to detect microplastics in environmental samples, such as soil, sediments, water, and biological systems, have been discussed. Few possible control measures from individual and industrial point of view, to reduce or mitigate the extent of microplastics contamination in the mere future, have also been provided.

\section{Microplastics, a global threat of the marine ecosystem}

Microplastics (MPs) exist in different forms in the environment, and generally occur in the size of less than 5 milli meters. They are classified as primary and secondary whether they are manufactured in microscopic size, or acquired from the breakdown of larger plastics, respectively. Primary microplastics are plastic pellets that are manufactured in microscopic size to be used in the plastic industry, personal healthcare products, such as facial cleansers and cosmetics. Secondary microplastics are obtained, due to deterioration of larger plastic debris by photooxidative, thermal, chemical degradation and/or mechanical abrasion (Fig. 2). The degradation rates of plastic wastes present in environment is much slower, and even a single plastic bag will take thousands of years to get completely removed.

Polymeric substances are one of the major building blocks that decides the chemical structure or properties of a particular microplastic particle. The polymers, such as polypropylene (PP), polyethylene (PE), polypropylene ether (PPE), polyethylene terephthalate (PET), polyester (PS) are some of the predominant ones that are extensively found, when studying the chemical composition of microplastics (Ivar do Sul 2021). The study of composition of microplastics is very much mandatory, when the toxicity assessment or a profile needs to be framed. Not only the polymers that are being used in microplastics, but also the chemical additives, 


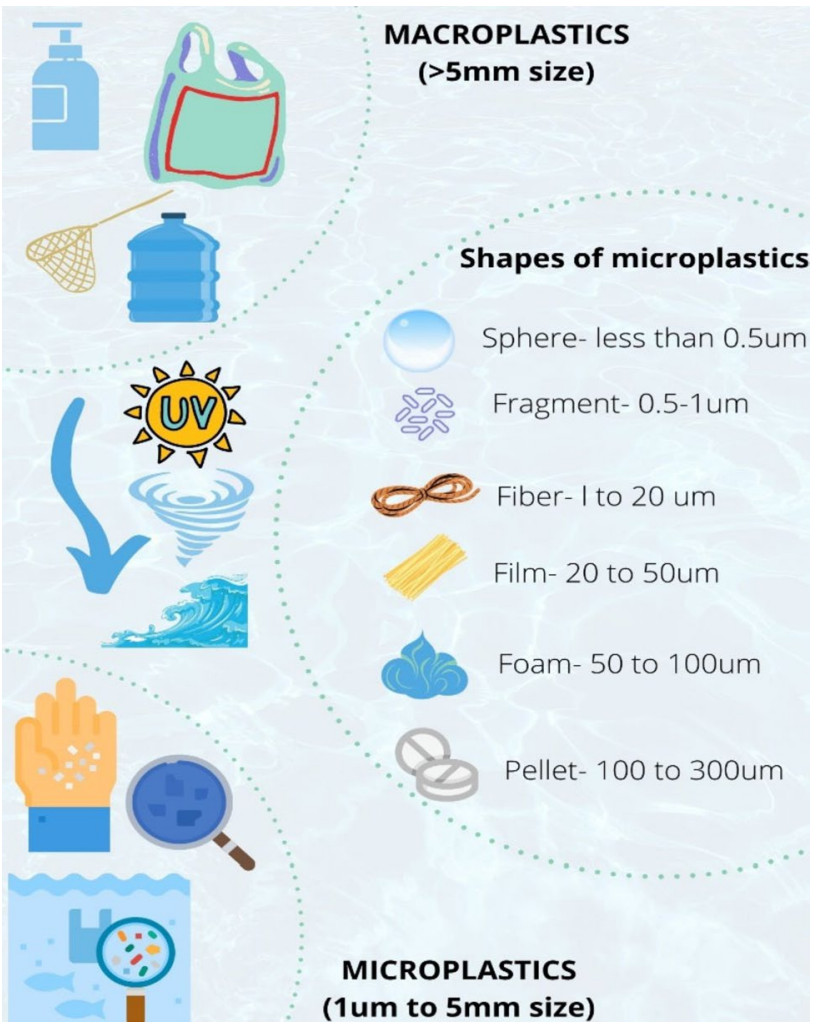

Fig. 2 Sizes and shapes of microplastics. Sizes: macro and microplastics. Shapes: spheres, fragments, fibers, films, foams, pellets

which are used to improve their structural properties, also contribute to toxic effects in living organisms during their leaching by weathering (Beiras et al. 2021; Hummel et al. 2021). Implication of additives of biological origin, instead of commercially applied additives may decrease the aquatic toxicity.

The fate and transport of microplastics are greatly determined by their physico-chemical properties. Size, one of the important physical properties of microplastics is found to have direct association with the biological responses of the aquatic organisms. Ma et al. (2020) reported that the microplastics, which were less than $100 \mathrm{~mm}$ in size, were readily ingested by the daphnids, since their food preferences are usually in this size (Ma et al. 2020). After ingestion by such planktonic crustaceans, due to their micro sized levels and higher retention properties, microplastics easily translocate within their body, and affect their dynamic way of food ingestion and their regular physiological activities. As these planktons are vital in maintaining the food chain of marine and coastal mangrove ecosystems, accumulation of microplastics within them can get transferred to higher trophic levels. A study conducted by Covernton et al. (2021) determined the factors affecting microplastics ingestion in fishes stated that clupeids had the highest concentrations of microplastics within their body (Covernton et al. 2021).
One of the major reasons could be that these fishes were planktivorous in nature, and consuming planktons that have ingested microplastics or microplastics that were in the similar size to that of planktons, as their major feed could have led to higher toxic effects. Depending upon the sources of contaminations, the size of microplastics in aquatic samples obtained from different regions varied. In general, the dominant form of microplastics that were observed in marine organisms, were majorly in the form of microfibres or fragments that might have resulted from fishing nets being used (Ma et al. 2020; Jung et al. 2021).

The shape of the microplastics present in the aqueous systems may be regular or irregular, and can indirectly affect various other properties, such as density of microplastics. For example, when present in their fibrous form or as films, the buoyancy would be higher, and they hardly settle in water, and are more available or exposed to the aquatic community in all subsurface of the marine system. Rather when present in the form of spherical particles, their chances of settleability or sedimentation would be comparatively higher. Jung et al. (2021), when studying the ecotoxicological effects of microplastics in different coastal systems, found that non spherical particles showed a higher risk of toxicity effects than spherical ones, and were found in abundance in the coastal waters than open seawater (Jung et al. 2021).

Colour of the microplastics is another physical property that affects the rate of ingestion by different trophic levels. Dark coloured microplastics, such as blue, black, and green were ingested in more amounts by the fish community than light coloured microplastics, and this may be because of their attractive nature or the similarity in colour with that of their original preys (Ma et al. 2020). Despite these reasons, the chemicals that have been used to provide bright colours to the polymeric substances are found to pose secondary toxic effects in aquatic systems. Gurjar et al. 2021 while studying the presence of microplastics in shrimps of Arabian Sea, reported that dark coloured microplastics especially black were present for about $30.16 \%$, followed by red within the shrimp body, and it may be because of their visual similarity to that of their prey (Gurjar et al. 2021). Other than physical properties, the surface properties of microplastics when coated with industrial chemicals, make them act as carriers for transporting toxic metals, such as rare earth metals and other pathogenic organisms to enter food chain through adsorption-diffusion mechanisms (Lee et al. 2021).

Hence, physico-chemical properties of microplastics, such as size, shape, colour, polymeric composition, and chemical additives have a vital role in deciding their fate, transport, and extent of toxicity in various organisms. The main sources that contribute to introduction of microplastics into environment have been discussed in the following section. 


\section{Sources releasing microplastics into the environment}

Urbanization is one of the main reasons for introducing microplastic contamination into water sources. Countless number of sources, such as wastewater treatment effluents, industrial discharges, leachate from landfills, household decors, etc., can directly introduce high concentrations of microplastics into freshwater and marine ecosystems. Many hydrological and meteorological parameters, such as rainfall, flood, runoff affects their spatial and temporal distribution within water systems, and decides the mobilization of their concentrations. The increase in microplastic load in wastewater treatment effluents may be due to accumulation of consumer products, such as PET bottles, Polyvinyl Chloride (PVC) pipes, Low density polyethylene (LDPE) containing plastic bags, microfibers from synthetic clothes, and other microplastic containing cosmetic products (Celis-Hernández et al. 2021).

Improper disposal of face masks that are being used during these COVID-19 pandemic situations release large number of fibrous polypropylene microplastics from nonwoven fabrics during their aging, and leads to accumulation of microplastics, in both water and air (Chen et al. 2021). Industrial discharges from plastic pellets manufacturing industries, cosmetic industries and textile industries may contain microplastics in their effluents, and ensuring proper treatment is mandatory.

The important drivers causing microplastics pollution in the Garonne River was urbanisation, which introduced microplastics into such large streams, and hydrological parameters were majorly affecting their temporal distribution within the stream (de Carvalho et al. 2021). During tourism and transportation by shipping, plastics wastes containing microplastics are being disposed of by human activities into open water sources and deterioration by external forces, such as weathering, climatic conditions lead to increasing concentrations within the coastal and marine environment. The plastic equipment and devices used in port activities and fishing nets also contribute to release or introduction of microplastics into marine water.

These microplastics not only remain as free-floating substances in surface water sources, but the higher density particles also deposit on the lake and seabed, leading to plastic deposition in marine environments (Nigamatzyanova and Fakhrullin 2021). Such plastic deposition may affect the health of coral reefs of underwater and fisheries that are inhabiting and lead to serious threats. Urbanisation, industrialisation, and improper waste management being some of the major sources, the occurrence of microplastics in environmental samples are discussed below.

\section{Occurrence of microplastics in environmental samples}

The urbanization and industrialisation from the past few decades, has increased the application of microplastics and due to continuous usage, their spiked levels of concentrations are being observed in almost all the environmental samples. Many of the freshwater and marine sources are more prone to these microplastics contamination, and the bioaccumulation within organisms pose serious threat to the ecosystem.

Analysis of microplastics in surface water samples of Arakawa River watershed in Tokyo, revealed that 10 out of 12 sites had mean microplastic concentrations of 1.8 pieces/ $\mathrm{m}^{3}$ and higher concentrations were observed at tributaries, located near highly populated metropolitan areas (Sankoda and Yamada 2021). In all its form, they are found to pose different kinds of issues to human and animal life. As physical particles, they easily enter the food chain by consumption by organisms of lower trophic levels. Their chemical composition comprising polymeric substances and additives cause toxic effects to living beings, and acts as adsorbent for adsorbing other organic pollutants based on their surface functional groups. The increased surface area of the microplastics can act as an anchorage support for the microorganisms to adhere to, and they colonize or form biofilms over the microplastic surface (Daniel et al. 2021).

Transmission to humans through sea aquaculture products is one of the possible ways, by which, humans get exposed to microplastics. As shellfishes such as crustaceans and cephalopods are majorly taken during seafoods, Daniel et al. 2021 checked for the presence of microplastics in tissues of shell fishes in Kerala (Daniel et al. 2021). While detecting a total of 180 samples of shellfishes, 2 out of 4 samples had microplastics in their edible tissues, and proved that consuming them may increase the load of microplastics within the human body, paving a way for bioaccumulation in future.

Processed dried fishes are consumed for food in many countries after excision (removal of viscera and gills) in the form of eviscerated fish (fish after excision of viscera and gills) to reduce contamination. The excised organs of 110 species of marine fish from Malaysian fish markets were examined for the presence of microplastics in them, as they are often used as ingredients in farm feeding operations, and on analysis, it was found that plastic polymers were found in predominance, accounting for about $78 \%$ of the detected microplastics particles (Karbalaei et al. 2019). Karami et al. 2017 analysed the presence of microplastics in excised organs and eviscerated fishes of dried fish samples, and found that the load of microplastics particles was higher in eviscerated fishes, showing that excision alone cannot provide reduced contamination, and still accumulate microplastic particles within human bodies, leading to toxic effects (Karami et al. 2017). 
In case of freshwater, zebrafish was one of the representative experimental models that was used to perform ecotoxicological studies by many researchers. The exposure to microplastic concentration of $4 \times 10^{4}$ and $4 \times 10^{6}$ particles/ $\mathrm{m}^{3}$ to zebra fish by Guimaraes et al. (2021), caused oxidative stress, REDOX imbalance, neurotoxic and cytotoxic effects, proving that even environmentally relevant exposure levels can induce bioaccumulation in aquatic organisms (Guimarães et al. 2021). Ragusa et al. 2021 for the first time, analysed placenta samples obtained from pregnant women from Italy for the presence of microplastics, and when detecting using Raman Micro Spectroscopy, 12 microplastic fragments were found in four placental samples, in which polypropylene type of polymers were found to be the predominant ones (Ragusa et al. 2021). Ibrahim et al. 2021 tested for the presence of microplastics in 11 colectomy samples from adults of North-eastern Malaysia, and detected that all of them had microplastics with an average of about 331 particles/specimen with filaments and fibrous forms, accounting for about $96.1 \%$ of the detected microplastics (Ibrahim et al. 2021).

Table 1 provides a summary of toxicity experiments that have been performed in various model organisms to analyse the toxicity extent of microplastics. The widespread occurrence of microplastics in different trophic levels urges the need for detecting their levels in environmental samples, and the advancements in analytical techniques have been discussed in next section.

\section{Analytical techniques for the detection of microplastics}

Sample collection is the primary step for detecting microplastics in environmental samples, such as water, air, sediments, and biota. Based on the study that is to be performed, the sample areas, sample depth and number of the collection sites need to be decided. Zooplankton nets with collection containers of desired size and manta trawls are used in some cases for sample collection (Razeghi et al. 2021). During sample preparation, pre-treatment by digestion using acids, alkalis or enzymes are some of the preferred methods, when dealing with environmental samples, and a single or multistep digestion processes may remove any organic or inorganic constituents, if present. Chemical digestion using $10 \%$ w/w Potassium hydroxide $(\mathrm{KOH})$ for $8 \mathrm{~h}$ at $60^{\circ} \mathrm{C}$ and wet peroxidation using $30 \% \mathrm{w} / \mathrm{w}$ of hydrogen peroxide $\left(\mathrm{H}_{2} \mathrm{O}_{2}\right)$ for $16 \mathrm{~h}$ are commonly conducted to remove the organic contents in water samples (de Carvalho et al. 2021).

In case of biological samples, samples are dissected, macerated, or enzymatically digested in the presence of phosphate buffer saline, to prevent rupturing of the sample. Then, they are centrifuged at respective conditions to remove any unwanted debris, and the aliquot of supernatant is then analysed using detection techniques (Guimarães et al. 2021). Proper washing and filtration after performing digestion should be checked to prevent the loss or underestimation of microplastics present in the sample. Prevention of contamination and purification of samples to remove other organic contaminants can prevent cross contamination, while performing detection using high-end techniques.

Over the past few years, visual identification was the most employed technique for the separation of microplastics based on their physical properties, such as size, shape, and colour. As it could not provide an accurate method of segregation, and may underestimate the particle sizes that are very small in size, researchers started moving towards advanced detection techniques. Pyrolysis-gas chromatography was used by Fischer and Scholz-Bottcher et al. (2017) to detect microplastics in fish samples, during which the generated pyrolysis products constituted the polymers present in the microplastics (Fischer and Scholz-Böttcher 2017). When Gas Chromatography-Mass Spectroscopy (GC-MS) analysis was conducted to those samples, a selective quantitative detection of the microplastic concentrations was found to be analysed using this technique. The technique was very advantageous, as it required no pre-treatment steps, but the analysis of small volumes each time was time consuming.

To provide improved detection of microplastics, a combination of microscopic techniques, such as Scanning Electron Microscopy (SEM) and Transmission Electron Microscopy (TEM) with other detection systems like Energy Dispersive $\mathrm{X}$-Ray Spectroscopy, were developed to provide a better understanding of the chemical composition, as well as its elemental analysis (Silva et al. 2018). Stereomicroscopy, an advanced optical microscopic technique was then developed to detect three-dimensional structures of different sized microscopic particles present in samples along with their colour diversity (de Carvalho et al. 2021).

Fourier Transform Infrared (FTIR) spectroscopy came in, to provide a more detailed chemical characterization of microplastics in environmental samples, and were very successful for polar microplastics. Attenuated Total Reflection (ATR) FTIR spectroscopy, an advanced spectroscopic technique was found to be an effective detection technique for polymeric detection in microplastics, but their higher cost of detection hindered their application (Vidyasakar et al. 2018; Utami et al. 2021). In Micro-FTIR techniques, an optical microscope was combined with an FTIR spectroscopy, providing a good detection of even the smallest sizes of microplastics present in the samples (Daniel et al. 2021).

Combining microscopic techniques with Raman spectroscopy can provide useful detection for non-polar microplastics, but prior purification and sample degradation needs to be checked, to avoid analytical errors. To avoid such errors, many optical techniques have been developed for detecting microplastics in environmental samples. Asamoah et al. 


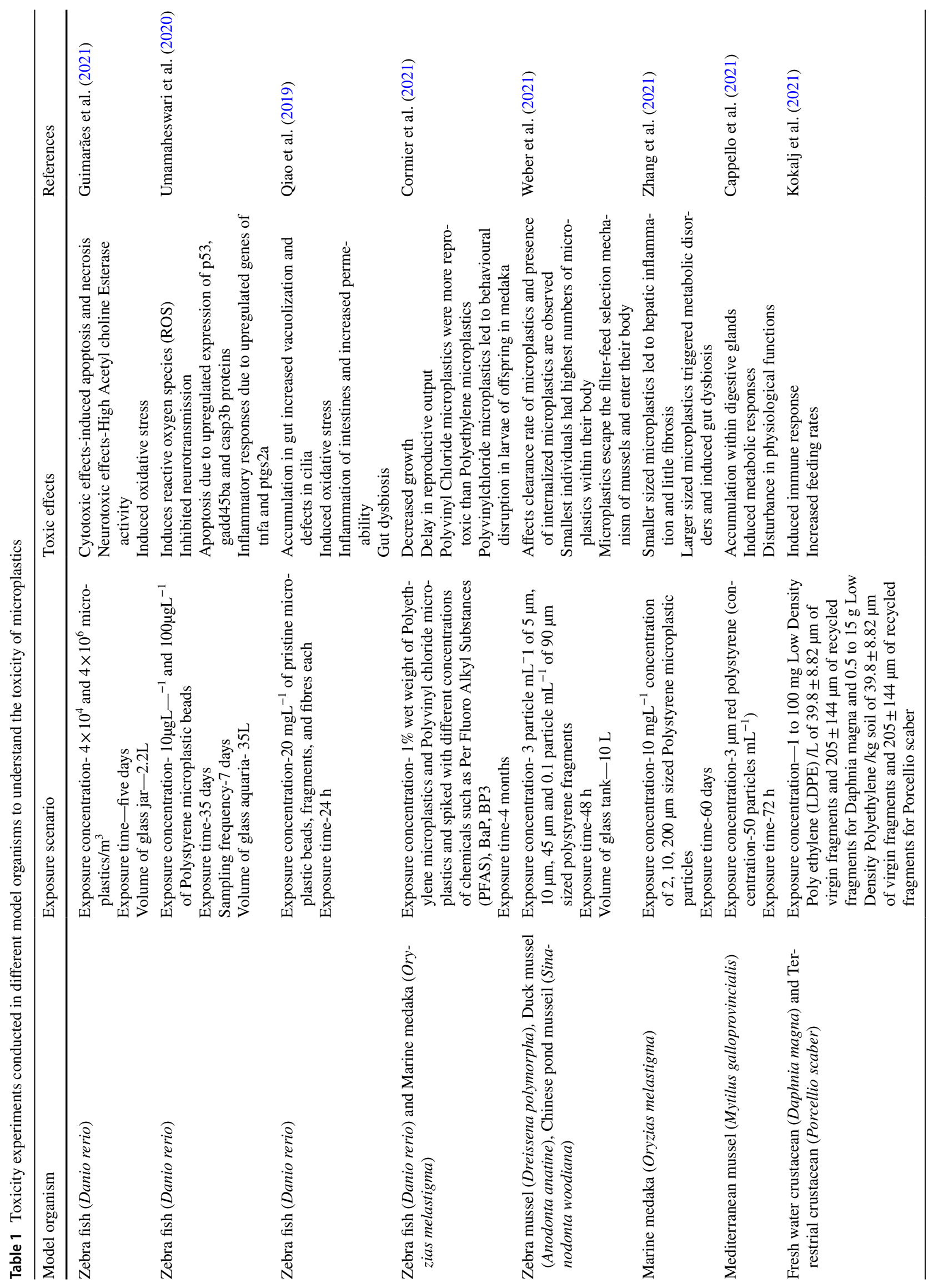


(2021) compared different optical based detection techniques like Raman microscopy, transmission spectroscopy, DOE (Diffractive Optical Element) based sensor and laser based optical methods for applying them in detection of microplastics in wastewater treatment sludge (Asamoah et al. 2021). The comparison revealed that sensor-based techniques were useful for qualitative measurements of microplastics in sludge samples, whereas, the microscopic and spectroscopic techniques proved their best in quantitatively detecting the microplastics in sludge samples.

A hyperspectral imaging system was developed by Zhu et al. (2021) by modifying and optimizing the commercially available ones, and when applied for microplastics detection in environmental samples, the modified technique rapidly detected the smaller sized microplastics of about $100 \mu \mathrm{m}$ in size (Zhu et al. 2021). Staining using dyes such as Nile Red, and detecting them based on their fluorescence properties, are used in some studies for easier detection of microplastics, but this technique may be inappropriate when microplastics have low hydrophobicity (Costa et al. 2021; Lv et al. 2021). A list of detection techniques that have been used till now for analysing microplastics in environmental samples, have been summarized in Table 2. Such advancements in analytics would make detection of microplastics in environmental samples easier. A brief discussion on mangrove ecosystem, and the extent of microplastic detection in such sensitive ecosystem till now, is as follows.

\section{Mangroves from the view of the ecology regulator}

Mangrove ecosystems covering about $132,000 \mathrm{Km}^{2}$, is a transitional intertidal ecosystem found in the subtropical and tropical shores between $30^{\circ}$ North and $30^{\circ}$ South latitude (Martin et al. 2019; Deng et al. 2021). They are key providers of crucial ecological services, such as carbon sequestration, food and water provision, coastal protection and habitat for marine life, environment purification and climate regulation (Ragavan et al. 2019; Wang and Gu 2021). Aside from this, the most salient service is protecting coastal areas from natural disasters, such as tsunamis and hurricanes (Luo et al. 2019; Deng et al. 2021). Indonesia has the largest mangrove covers in the world, covering an area of about 250,000 hectares, followed by Australia and India. Figure 3 shows the top 15 countries, having highest mangrove coverages, contributing to the global mangrove distribution (from data obtained till 2014) (Casey and Hamilton 2016).

\section{Components of mangroves}

Each mangrove region has their own representatives of flora and fauna species based on their climatic conditions, topography, salinity, and other factors. Being carbon-rich forests, they regulate the nutrient cycles within ecosystem, and act as a hotspot of rich biodiversity. Based on the changes in tree structures of mangroves, these forests can be classified into different types: (a) Fringe forests are the areas that are nearer to the river side, more prone to tidal disturbances, and are often found to confer shoreline protection. Tree species with prop roots or pneumatophores dominate this area (Ghosh et al. 2015), (b) Basin forests are present in the interiors of mangroves, and are partially or regularly flooded by water based on the seasonal changes. Tree species that reside in this region experience a stunted growth, due to the stagnant or low flowing water levels, (c) Hammock forests are similar in nutrient and salinity patterns to that of basin forests, but occur at elevated levels than basins, (d) Over washed forests appear as islands of landmass extending over narrow areas, and due to frequent tidal disturbances, only saline tolerant species inhabit in these areas, (e) Dwarf forests appear during colder climate and lack of nutrients, and due to such extreme stress conditions, only few species can thrive in these type of mangrove forests, (f) Riverine forests grow along the flowing rivers for several kilometres, and the balanced tidal patters, nutrient availability, salinity, runoffs and sheltered areas make them serve as a hub for a variety of mangrove species (Ewel et al. 1998).

The diverse species of flora and fauna present in mangrove forests are unique in their nature, due to their nutrient rich environment, and are region specific to respective geographical areas and conserving those needs special attention. Ibrahim-Bathis et al. (2021), when exploring the northern coast of Kerala found that trees belonging to genus Avicennia and Rhizophora, dominated the coastal mangrove region (Ibrahim-Bathis 2021). The medicinal plants and plant extracts obtained from mangroves are used by traditional medical practitioners of various countries over years, due to their antioxidant, anticancer and antidiabetic properties (Sasidhar 2020).

The natural filter and trap mechanism in the pneumatophores of most of the fauna, prevents the entry of foreign components into the ecosystem, and naturally protect the coastal areas from getting eroded. Pneumatophores that help in gas exchange reactions in the mangrove forests, also release other toxic chemicals adsorbed by the trees through this mechanism, and act as sieve for inhibiting the entry of large sized objects into this ecosystem (Martin et al. 2019). The trees also provide shelter for many migratory and coastal birds, amphibians, reptiles, and they serve as a breeding and nesting hub for thriving their populations. The time spent by coastal and marine organisms in mangroves are integral part of their life cycles, and serves as a hub for these dependent organisms. The sediments of mangroves inhabit rare species of crustaceans and molluscs, and the tides of coastal regions bring a variety of fishes to this mangrove ecosystem. 


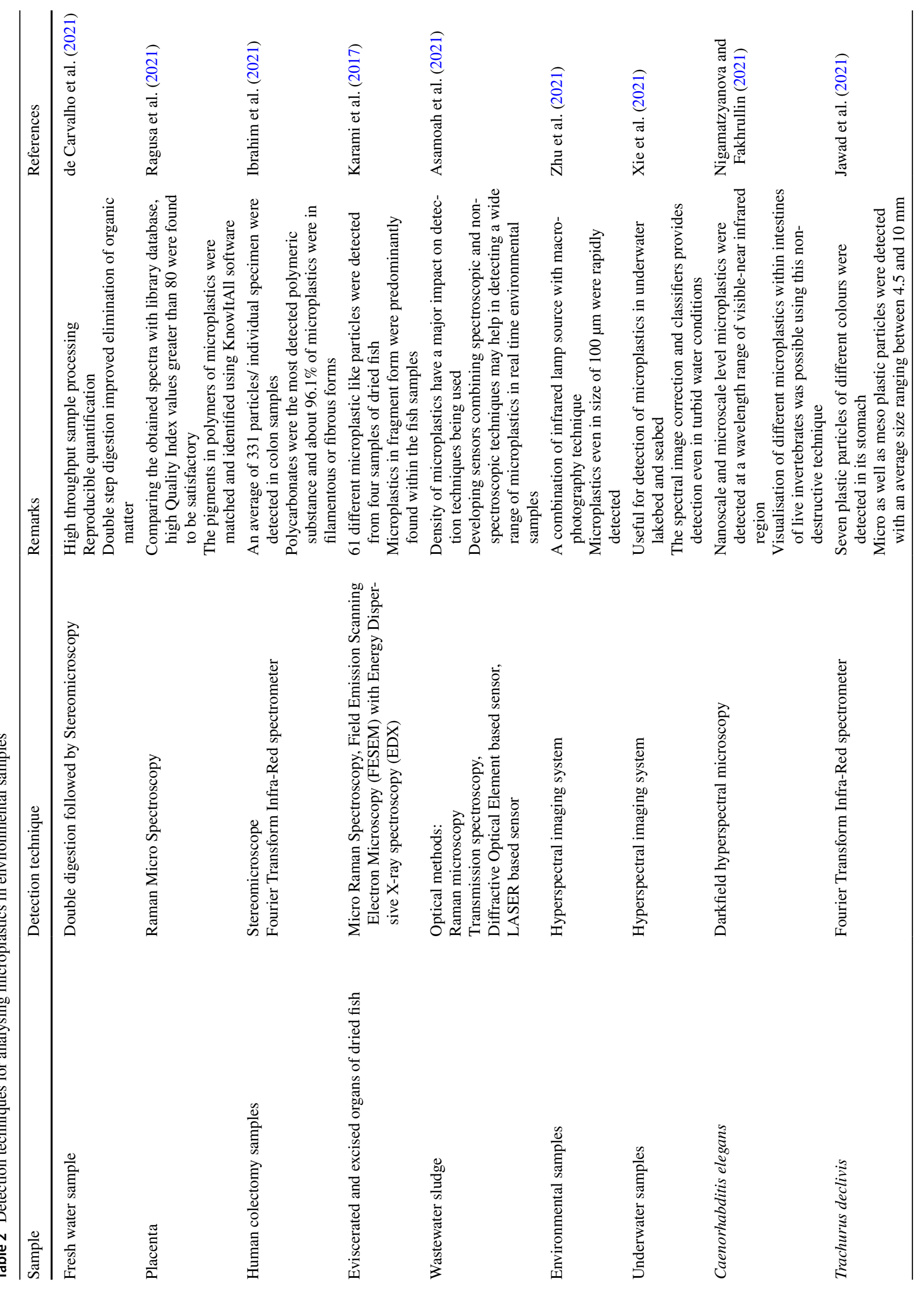




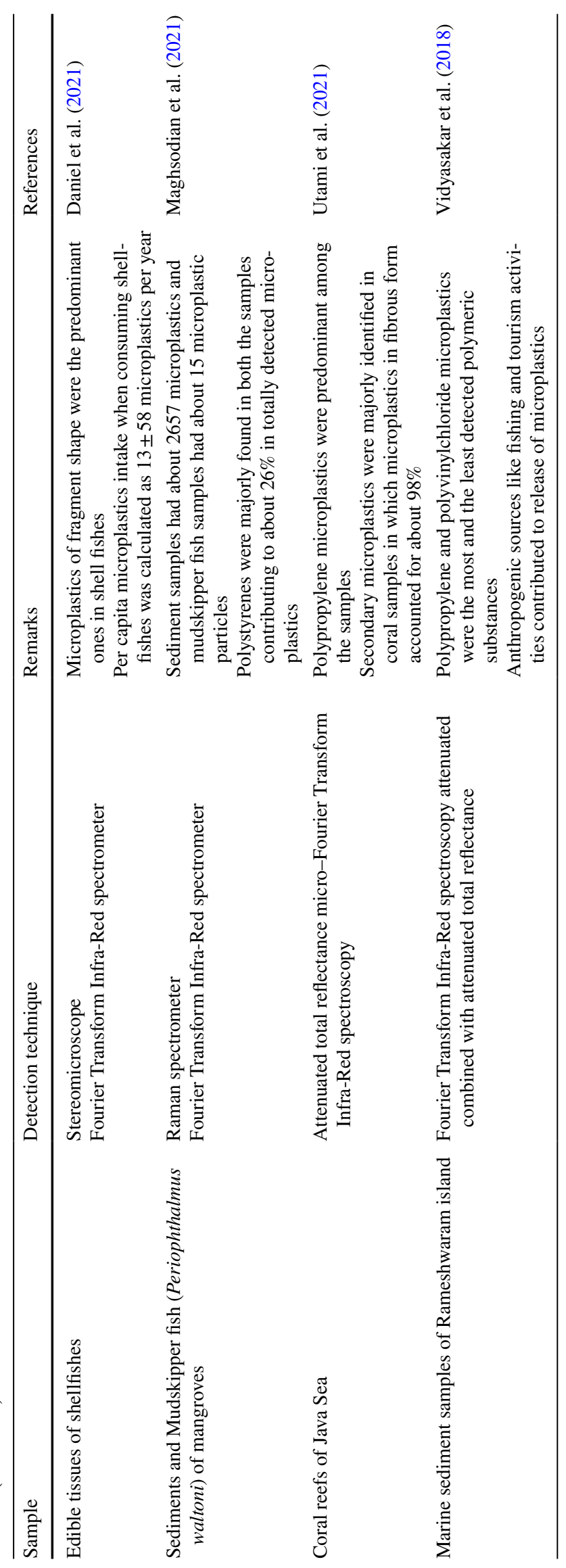




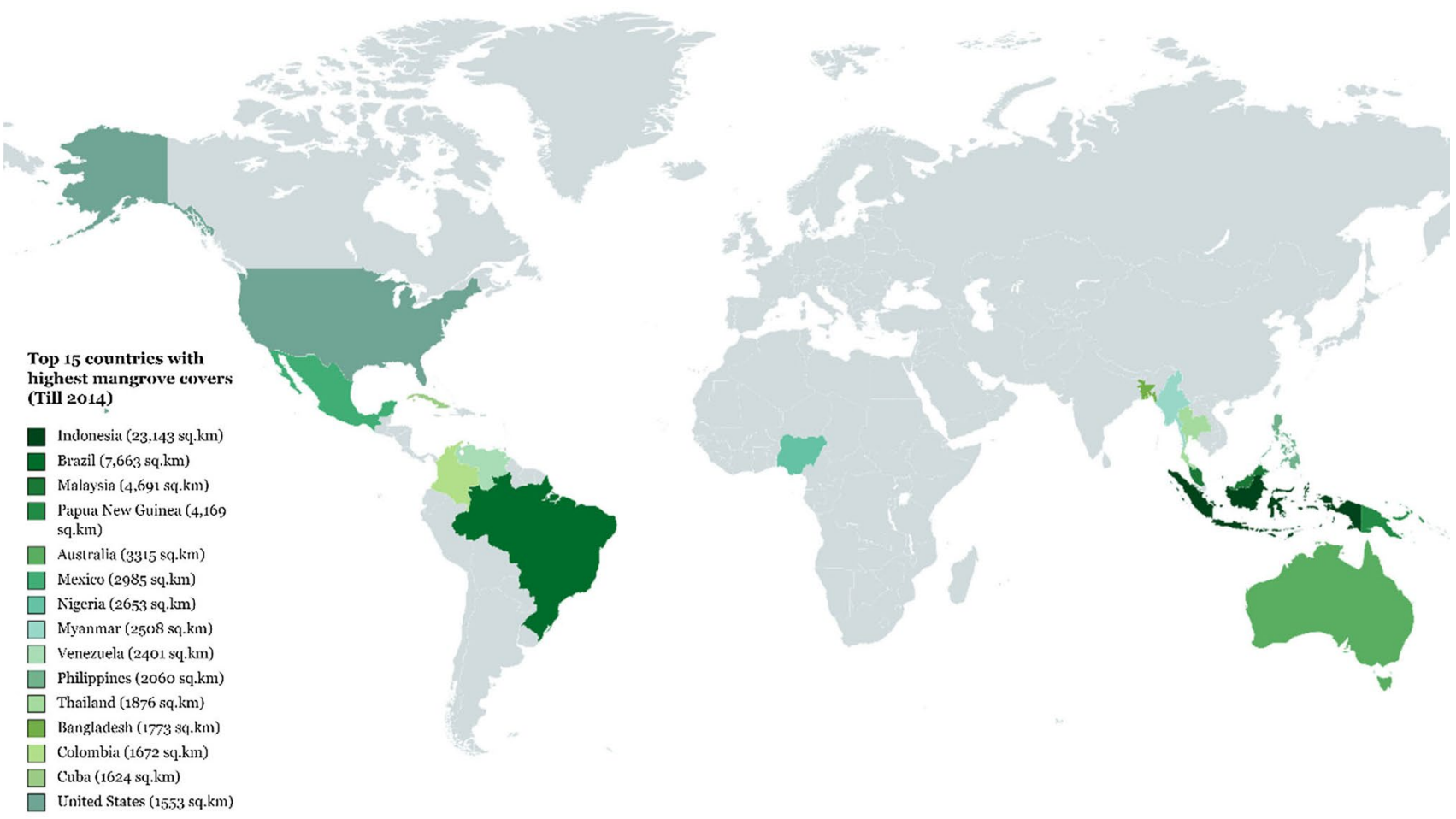

Fig. 3 A map showing top 15 countries that are covering highest mangrove areas among global mangrove forest distribution

The diverse microbial community that resides naturally have the capacity to perform ecological purification through transformation or degradation of the pollutants. The sediment trapping mechanism of mangroves adsorb various contaminants that enter the system, and either, they get transformed through rapid conversion or remains adsorbed along with sediments that may lead to long term effects (Maghsodian et al. 2021). In a single note, mangrove forests exist either as tide-dominated, river-dominated, or interior forests, offering a variety of economically valued goods and commodities for the living beings through their services, such as logging, fishing, shelter, quality plant products, etc., Being one of the sensitive ecosystems, the ecological health of mangroves gets easily affected due to changes in quality of environment by manmade activities like urbanization, desertification, logging, soil acidification, sea level rising, $\mathrm{CO}_{2}$ concentrations, road construction etc., and other natural parameters, such as temperature, rainfall, drought, topography, weathering, etc. These activities seriously affect the flora and fauna of the ecosystem, and lead to adverse effects on these living beings (Yudha et al. 2021).

The extent of microplastic contamination in mangrove ecosystems, and their associated living organisms due to such activities, are discussed in the following section.

\section{Microplastics in mangroves}

The increased anthropogenic activities carried out in both coastal and nearer mangrove areas might introduce many sorts of contaminants into these mangrove ecosystems by improper waste management practices, affecting their ecological health. Many benthic organisms, such as crustaceans, mussels and bivalves reside over the coastal side of these mangroves, and being deposit-feeders, their chances of ingesting microplastics present in the sediments of mangroves are higher. Land based sources for introducing microplastics into this ecosystem include industrial effluents, water treatment plant discharges, etc., whereas the ocean-based sources include tourism, fishing supplies, etc., Water current and weathering are few drivers that aid microplastics reach the mangrove ecosystems, leading to bioaccumulation within living organisms (Wang and $\mathrm{Gu}$ 2021). Due to such drivers, studies should account samples of soil, water, and sediments to calculate the extent of contamination within this ecosystem. Recent studies on investigating the extent of microplastic contamination in mangroves, have detected their presence in different samples. 


\section{Sediments}

An investigation carried out by Cordava et al. (2021) in Muara Angke Wildlife reserve of Indonesia, showed that an average microplastics of $28.09 \pm 10.28$ particles $/ \mathrm{kg}$ of sediments were present, in which the outside areas of mangroves were more prone to higher concentrations of microplastics than inner side, due to tidal patterns (Cordova et al. 2021). The spatial distribution of microplastics in sediment samples of mangroves of Southern Brazil, was analysed by Zamprogno et al. (2021) and it reported that less preserved sites of basin areas that were prone to human activities were more susceptible, and had higher microplastic concentrations than fringe areas due to stagnant, low flow or weak tides (Zamprogno et al. 2021).

\section{Marine canopies}

Marine canopies are formed underwater in this ecosystem by plants such as seagrass meadows, and they inhabit and provide shelter for a wide range of fishes and invertebrates (Unsworth et al. 2021). The particle trapping ability of these canopies are dependent on the tidal patterns, and so, contamination in these areas may deposit particles within this megafauna. De los Santos et al. (2021) tried simulating such canopies, using seagrass meadows (Zostera marina) in a hydraulic flume, and found that density of shoot of meadows, density of microplastics and flow velocity are important parameters that had direct influence on deposition of microplastics within these canopies (de los Santos et al. 2021). The simulation studies also proved that low flow velocities aided in deposition of both dense and floating polymeric substances, whereas under high flow velocities, the deposition of any kind of particles could not take place suggesting that under certain conditions these marine canopies may serve as sinks of microplastics.

Similar current generating flume was used by de Smit et al. (2021) to assess the mechanism of microplastic trapping by three specimens that were, sea meadows, macroalgae and corals, which are predominant in nearshore habitats (de Smit et al. 2021). Having larger surface and architectural complexities, corals had the highest number of microplastics within them, and greater than $90 \%$ of smaller sized microplastics got entrained within the sediment samples. Yin et al. (2021) sampled the reeds present in wetlands of East Dongting lake, China to determine the presence of microplastics, and found that an average of $511.2 \pm 295.0$ items $/ \mathrm{kg}$ of microplastics were present, confirming that the abundance of microplastics could have emerged from lakes and other fishing activities (Yin et al. 2021).

\section{Fishes}

As fishes and benthic organisms obtained from mangrove areas serve as food for many communities, recent research has started testing the presence of microplastics in them. Contamination in food samples would be an indicator that these pollutants may get transformed and accumulated through the food chain to higher trophic level organisms. Maghsodian et al. (2021) analysed the presence of microplastic particles in sediments and fish samples of Periophthalmus waltoni in mangrove forests of Southern Iran, and concluded that polystyrene and polycarbonates were the most $(26 \%)$ and least $(3 \%)$ detected polymers in both the samples (Maghsodian et al. 2021).

The presence of microplastics in mudskipper fishes of Ulhas River estuary in India was investigated by Kumkar et al. (2021) and the findings stated that the feeding selectivity of these fishes, inhibited the entry of large sized microplastics into the body, and $70 \%$ of filament kind of microplastics were observed in their gut region (Kumkar et al. 2021). An average range of 3.75-6.11 particles per fish were found to be present and being a part of seafood in many countries, mudskippers show an alarming threat towards bioaccumulation aspects. Maghsodian et al. (2021) tried investigating the presence of microplastics in 14 different species of commercial fishes that were purchased from markets of northern coast of Persian-gulf region. Gills of Thunnus tonnggol fish species and the gut region of Sphyraena putnamiae species had the highest microplastic concentrations of about 5.71 particles/individual and 5.67 particles/ individual with fibers being the predominant forms, and also showed that fishes belonging to pelagic region, had higher microplastic accumulation than those of demersal region (Maghsodian et al. 2021).

\section{Microbes}

As rhizosphere inhabiting microbes, are majorly responsible for maintenance of the subsoil system and other nutrient cycles in mangroves, the impact of microplastics on such organisms are also being studied in recent days. Xie et al. 2021 tried studying the colonization of rhizosphere microbes on microplastic surfaces, and interestingly found that other than rhizosphere microbes that showed biodegradation towards microplastics, few pathogenic organisms, such as Vibrio parahaemolyticus and Escherichia Shigella, were also persistent along with microplastics and soil (Xie et al. 2021). The predominance of polystyrene, polypropylene and polyethylene-based polymers in mangrove sediments may be because of fragmentation of food wrappers and textiles disposed during maritime transport, and from the fishing gears used during fishing activities (Cordova et al. 2021). 
In recent days, bioremediation of microplastics using microorganisms is being preferred over other remediation techniques. In this method, microbes that produce microplastic degrading enzymes, such as PETase, hydroxylases, peroxidases, etc. are utilized for the remediation or degradation of microplastics. The polymer type, properties, molecular weight, and chemical additives used in microplastic making, are some of the important factors that may affect the extent of microbial degradation of microplastics. Initially, the microbes form biofilms around the microplastic structure, and secretes the enzymes that are responsible for the conversion of polymers to monomeric substances. Then, these monomers are ingested within their body, and are completely degraded or metabolized to simpler compounds, such as carbon dioxide, water, etc, (Jeyavani et al. 2021). Such degradation may seem to occur at a slower rate, but as it is an eco-friendly approach, modifying the microbial strains using genetic engineering techniques may enhance their degradation potential and confer them with higher abilities.

Focussing future research on scaling up such microbial degradation of microplastics, and producing polymeric substances of biological origin from plants, animals, fungi, and bacteria, such as polyhydroxyalkanoate (PHA), polylactic acid (PLA) and polybutylene succinate (PBS) may help in moving towards circular economy and renewable sources. Another sensitive ecosystem of marine environments, the coral reefs, their ecological importance, and level of microplastic contamination, are shown in the next section.

\section{Coral reefs as an indicator of matured and balanced ecosystem}

Coral reefs form an integral part of ecosystem in marine environment comprising of coral polyps held by a skeleton of calcium carbonate. Other than its high income through fisheries, the barrier forming effects of reefs make them act as a natural barrier in regulating the tidal effects, generators of oxygen, absorbs atmospheric carbon dioxide, and are fed by some lower trophic level organisms that resides in marine environment (Soares et al. 2021). The structural complexity of the corals, such as tubular, branched, etc. offers shelter capacity to greater than $25 \%$ of the underwater biodiversity, and acts as a predative ground for many invertebrates and fishes (Urbina-Barreto et al. 2021). Being sensitive ecosystem, coral reefs get easily affected by environmental pressures, posed due to climatic changes, global temperature changes, ocean acidification, pollution, urbanization, fishing activities, oil spills, marine litter, mining, etc. On getting exposed to such cumulative pressures, the mortality rates of corals and its associated organisms, such as algal turfs, fishes, gets increased, and having an important role in initiation of food chain in marine ecosystem, they gradually affect the life of higher trophic levels (Tebbett and Bellwood 2021).

The deterioration of corals also fuels the replacement of seaweeds into this ecosystem, creating a phase shift within the ecosystem. Therefore, saving these coral reefs should be focused to protect this sensitive ecosystem. Spadaro et al. (2021) had reported that Maguimithrax spinosissimus, a herbivorous crab, has a natural grazing ability towards seaweeds, and employing them could help in re-shifting from seaweed dominance towards coral restoration aspects (Spadaro and Butler 2021). Adaptation to pressures can naturally recover the deteriorated reefs but in recent years, as the pollution emission rates are higher, the natural recovery rates are getting lowered. Declaration of marine protected areas to conserve these species and strict regulatory policies must be focussed along with fisheries management practices. The occurrence of microplastics in corals and other reef dwellers due to marine plastic pollution, is as follows.

\section{Occurrence of microplastics in corals}

In recent years, the increased marine plastic pollution has been found to affect the coral lives, due to which severe deterioration is found to occur. Being non-selective feeders, corals consume smaller size organisms, such as zooplanktons, and gets fed by microplastic particles present in water due to their size similarities. These microplastics when ingested and accumulated within corals, cause severe tissue damage, affect their immune system, reduce their food intake, affect growth, cause necrosis and bleaching (Utami et al. 2021). The ingestion and retention time of microplastics within marine organisms, greatly depends on the size of organisms, microplastic size and concentration of microplastics in the aqueous environment. Pathogenic microorganisms and chemicals carried along with microplastic particles can also cause toxic effects and other associated diseases on coral reefs. Organisms that feed on coral tissues and their associated algal species, such as marine worms, fish species, etc. also gets exposed to their toxic effects experiencing bio accumulative effects.

The corals of Hainan island along with its associated reef dwellers, were sampled to detect the contamination of microplastics by Jia et al. (2021). After extraction and detection, it was seen that all samples from living environments of these corals that are seawater and sediment samples had an average of $14.90 \pm 7.76$ particles $\mathrm{L}^{-1}$ and $343.04 \pm 266.13$ particles $\mathrm{kg}^{-1}$ with microplastics particle size less than $1 \mathrm{~mm}$. As reef dwellers within this environment have varied feeding mechanisms, the ingestion of microplastics varied based on their trophic levels, and experienced an induction in apoptosis. An analysis by Utami et al. (2021) on detection of microplastics in reefs of Java sea, Indonesia, stated that secondary microplastics were the major sources for contamination in this region, during which biofouling of the 
microplastics increased the particle density to reach the sea floor and entangle within the carbonate sediments (Utami et al. 2021).

A coral reef fish species, Pomacentrus moluccencis was chosen as the model species to detect the microplastic pollution in surface water samples of Great Barrier Reef of Australia by Jensen et al. (2019). Among the detected particles, fibrous forms were abundant in the samples, determining that riverine discharges were one of the potential sources for inshore contamination. The spatial distribution of microplastics in sand samples of a fringing reef, and an atoll of coral reef islands of South China Sea, was analysed by Zhang et al. (2019). Red coloured polypropylene microplastics of size less than $1 \mathrm{~mm}$ were detected in larger quantities than other types and ocean currents, water exchange rates, etc., were the major factors responsible for the deposition of microplastics in these samples, showing an average microplastic concentration of $40 \pm 4$ items $/ \mathrm{kg}$ to $610 \pm 11$ items/ $\mathrm{kg}$. Such increased occurrence would impose toxicological impacts on corals and their discussion is as follows.

\section{Toxicological impacts of microplastics on corals}

Many toxicity experiments on coral species have been conducted by exposing them to environmentally relevant concentrations, and to projected higher concentrations of microplastics to know their varied toxicological effects.

Mendrik et al. (2021) tried studying species specific impact of different forms of microplastics on two species of corals, Acropora species and Seriatopora hysterix during which fibrous microplastics affected their feeding behaviour, leading to initiation of stress responses (Mendrik et al. 2021). Exposing Acropora species to microplastic fibres for a period of 12 days decreased their photosynthetic activities to about $41 \%$, and so more research needs to be focused on these aspects. Hankins et al. (2021) tried evaluating the toxicity effects of microplastics on two scleractinian coral species, Pseudodiploria clivosa (large polyp) and Acropora cervicornis (small polyp) that are commonly prevalent in Atlantic region. The long-term chronic exposure to polyethylene microplastics showed reduced calcination and tissue surface area, thereby affecting the growth of coral skeleton (Hankins et al. 2021). The ingestion and stress response, initiated by exposing scleractanian coral species of Tubastrea aurea to different microplastic exposures, was studied by Liao et al. (2021).

Among various polymeric substances, PVC based microplastics caused more toxic effects than other polymers, and the exposure to smaller sized microplastics, had higher retention rates and interferences than larger sized counterparts (Liao et al. 2021). Toxicity studies by Grillo et al. (2021) on scleractanian corals of Porites porites stated that chronic exposures for a period of about $96 \mathrm{~h}$ led to incorporation of microplastics within the tissue structure, without showing any mortality effects (Grillo et al. 2021). Santana et al. (2021) exposed a coral reef fish, Pomacentrus amboinensis to polypropylene and polyester fibers for a period of $128 \mathrm{~h}$ and found that body burden increased with a lowered depuration rates of about 0.13 microplastics per hour to 0.52 microplastics per hour from the body (Santana et al. 2021).

Table 3 provides a conclusion of various toxicological studies that have been performed on coral species, by exposing them to different concentrations of microplastics. From the literatures, fibrous forms of microplastics were the predominant ones that were detected in most of the samples posing adverse effects, and their ingestion rates were higher, due to their easy escape from filter feeding mechanisms of organisms.

\section{Guidelines to reduce microplastics in the marine environment}

\section{Individual responsibilities}

Almost all the microplastics emergence into the environment arises due to anthropogenic or human activities. Our daily use products, such as textiles, teabags, paper cups, food containers, personal care products (PPCPs), face masks are some of the main sources of microplastics. Hence, creating awareness among the public is the first and foremost step that should be done to perform source reduction, and to mitigate the release of microplastics by humans. The concept of four R's that is reduce, reuse, recycle and recover should be inculcated within people's minds, so that people should try to reduce the usage of plastic materials, reuse the used plastic products in best possible ways, recycle the plastic products if possible, and should try to initiate some sorts of energy recovery processes (Calero et al. 2021).

\section{Industrial effluent regulations}

As industries producing daily use consumer products have a major chance of having microplastics in their effluents, strict regulations should be imposed globally by national and international authorities to ensure the level of microplastics in effluents. Paint industries use microplastics in their paint composition to provide protective coating to surfaces, and hence, they may emit microplastics into environment during all their processes, such as production, manufacturing, and disposal (Faber et al. 2021). So, paint industries must take appropriate measures in reducing microplastic release, and should opt for alternate compositions that may reduce or eliminate the requirement of microplastics in paints. Plastic industries are another major contributor of both primary and secondary microplastics. These industries should reduce overproduction of products, prevent leakage of plastic 


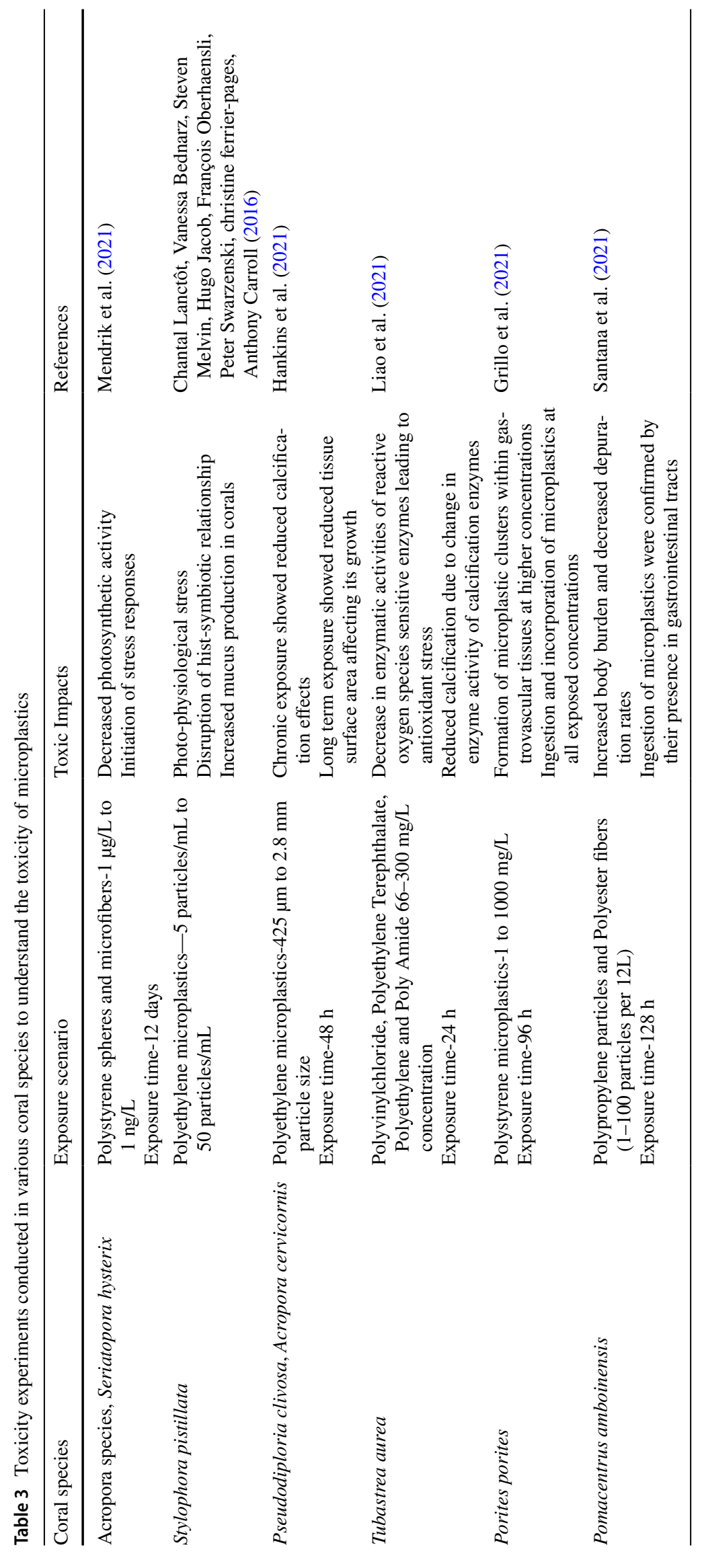


materials into environment, ban hazardous polymeric substances, and should ensure proper handling of their wastes. In case of textile industries, polyester clothing that are made of polyethylene terephthalate (PET), are having a global demand in markets. This polymer in the form of synthetic microfibres are used in clothing manufacturing along with other chemical additives, such as salts, toxic dyes, heavy metals, etc. (Carney Almroth et al. 2018). These microfibers are one of the finest forms of microplastics, and get easily released from the clothing during natural weathering and by abrasion during washing process. It has been reported that, in one single laundry wash, a single piece of polyester clothing is found to release an average of 600,000-15,000,000 of microfibers into the wash water, and finds their path directly into the water treatment plants (Palacios-Mateo et al. 2021). Such microfibers can easily enter the food chain of aquatic organisms and pose ecotoxicological effects.

\section{Advanced treatment technologies}

Opting filter balls or membranes that can adsorb the released microfibers onto its surface or using washing bags to hold the released microfibers into them, are some of the ways by which their release into environment can be reduced. As industrial effluents eventually reach wastewater treatment plants, improving conventional water treatment plants by implementing advanced treatment technologies may ensure the removal of micropollutants, and may reduce their concentrations before discharging them into open water sources (Calero et al. 2021). Treatment strategies like adsorption, and filtration can also be opted based on the microplastic type, composition and size that are predominantly found in aqueous systems (Padervand et al. 2020).

\section{Fishing and tourism regulations}

The advances in fishery industries have increased the usage of fishing supplies made of plastic materials, such as polypropylene, polyethylene, polyvinyl chloride, etc., The fishing nets, floats, fish boxes, crates, traps, barriers, weirs, line gears, packaging materials are used during fishing operations, and when improperly disposed into marine or coastal environments, the deterioration leads to continuous release of microplastics into aquatic environment, leading to toxicity effects. So proper checking of their disposal should be ensured. Disposal of plastic wastes during tourism activities should also be strictly restricted by the respected authorities to lessen their contamination through trophic level transfer of marine organisms.

\section{Proper waste management practices}

COVID-19 pandemic has increased the demand, usage and disposal of single used plastic materials, such as PPE kits, medical masks, gloves etc. and improper disposal of these substances increases the plastic load by constantly releasing micro as well as nano plastics, due to continuous weathering conditions during ageing (Chen et al. 2021; Wang et al. 2021). Wang et al. (2021) when subjecting the disposable masks to Ultraviolet (UV) weathering, had reported that one single weathering led to release of about 1.5 million microplastics into aqueous systems, whereas additional weathering by natural conditions, such as sand in coastal shorelines, promoted their release to more than 16 million microplastics from a single mask (Wang et al. 2021). As melt blown face masks provide enhanced protection among different types of masks, they are preferred and used by a larger number of people. Kwak and An et al. (2021) conducted a study on bio-fragmentation of microplastics from melt blown facemasks, and suggested that at higher concentrations in soil, more generation of micro and nanofibers were found to get released into the soil ecosystem, and they also posed reproductive as well as growth defects in springtails as well as earthworms (Kwak and An 2021). Masks that are fabricated using polymers obtained from biological origin other than chemical polymeric substances needs to be promoted, so that biodegradability of the masks can be ensured. Alternatives for chemical additives that are used along with polymeric substances in microplastics should also be produced to reduce their hazardous effects on living beings. Improper disposal in landfills or by any other means, not only poses threat to human life, but also to the wildlife that may interact with disposed masks during their ingestion or during other activities. When microplastics form minor tangles within aquatic system, smaller invertebrates may get entangled within them and pose serious health hazards (Patrício Silva et al. 2021). Therefore, proper management of plastic pollution is a prior responsibility to reduce the microplastic generation in environment, and to protect living organisms.

\section{Periodic monitoring of plastic pollution}

The extent of plastic pollution can be understood by organizing monitoring programs or awareness campaigns, and periodic investigations may provide their extent of pollution, by which appropriate measures need to be followed. After knowing their toxic impacts, from 2020, many countries like China, United States, United Kingdom, India have insisted complete ban, and formulated strict regulations on the usage of microplastics, single use plastic products and restrictions in tourism activities (Jeyavani et al. 2021). The Sustainability Development Goals (SDG) that covers the water quality goals should take the issues of microplastics in aqueous systems as a serious threat 
for the mere future, and should provide steps to mitigate their effects, while focussing on the sustainability issues.

\section{Conclusion}

Microplastics introduced into marine environment through anthropogenic activities have become a global concern, posing serious impacts. Detection of high concentrations of microplastics even in restricted areas of sensitive ecosystems, such as mangroves and coral reefs shows an alarming signal that more focus is needed towards this emerging threat. The transfer of microplastics through different trophic levels of the marine food chain shows their increased bio accumulative potential, and as many countries have seafood as a part of their regular diet, immediate addressing of the problem needs to be done by regulatory authorities. Alternatives to chemical additives being used along with polymeric composition of microplastics should be developed, as they create additional toxic impacts to microplastic exposed organisms. Reduction of plastic pollution caused due to daily use products could be the major way to reduce microplastic contamination in environment. Every citizen should consider mitigation of microplastics as a prior social responsibility, and must contribute their part from the initial stage of source reduction during waste management practices.

Acknowledgements Authors, Juliana John and Nandhini A R would like to acknowledge International Consortium of Water Researchers (ICWR) for providing the technical support through research internship.

Authors contribution JJ: Writing; NAR: writing; PVC: conceptualization, editing and supervision; MS: review and editing.

Funding No funding was received to assist with the preparation of this manuscript.

\section{Declarations}

Conflict of interest The authors declare that they have no conflict of interests.

\section{References}

aber M, Marinković M, de Valk E, Waaijers-van der Loop SL (2021) Paints and microplastics exploring recent developments to minimise the use and release of microplastics in the Dutch paint value chain. https://doi.org/10.21945/RIVM-2021-0037

Alimba CG, Faggio C (2019) Microplastics in the marine environment: Current trends in environmental pollution and mechanisms of toxicological profile. Environ Toxicol Pharmacol 68:61-74. https://doi.org/10.1016/j.etap.2019.03.001
Andrady AL (2011) Microplastics in the marine environment. Mar Pollut Bull 62:1596-1605. https://doi.org/10.1016/j.marpolbul. 2011.05.030

Asamoah BO, Salmi P, Räty J et al (2021) Optical monitoring of microplastics filtrated from wastewater sludge and suspended in ethanol. Polymers. https://doi.org/10.3390/polym13060871

Barboza LGA, Gimenez BCG (2015) Microplastics in the marine environment: Current trends and future perspectives. Mar Pollut Bull 97:5-12. https://doi.org/10.1016/j.marpolbul.2015.06.008

Beaumont NJ, Aanesen M, Austen MC et al (2019) Global ecological, social and economic impacts of marine plastic. Mar Pollut Bull 142:189-195. https://doi.org/10.1016/j.marpolbul.2019.03.022

Beiras R, Verdejo E, Campoy-López P, Vidal-Liñán L (2021) Aquatic toxicity of chemically defined microplastics can be explained by functional additives. J Hazard Mater. https://doi.org/10.1016/j. jhazmat.2020.124338

Calero M, Godoy V, Quesada L, Martín-Lara MÁ (2021) Green strategies for microplastics reduction. Curr Opin Green Sustain Chem. https://doi.org/10.1016/j.cogsc.2020.100442

Cappello T, De Marco G, Oliveri Conti G et al (2021) Time-dependent metabolic disorders induced by short-term exposure to polystyrene microplastics in the Mediterranean mussel Mytilus galloprovincialis. Ecotoxicol Environ Saf. https://doi.org/10.1016/j. ecoenv.2020.111780

Carney Almroth BM, Åström L, Roslund S et al (2018) Quantifying shedding of synthetic fibers from textiles; a source of microplastics released into the environment. Environ Sci Pollut Res 25:1191-1199. https://doi.org/10.1007/s11356-017-0528-7

Carpenter EJ, Anderson SJ, Harvey GR et al (1972) Polystyrene spherules in coastal waters. Science 178:749-750. https://doi.org/10. 1126/science. 178.4062 .749

Casey D, Hamilton S (2016) Creation of a high spatio-temporal resolution global database of continuous mangrove forest cover for the 21st century (CGMFC-21). Glob Ecol Biogeogr 25:729-738

Celis-Hernández O, Ávila E, Ward RD et al (2021) Microplastic distribution in urban vs pristine mangroves: using marine sponges as bioindicators of environmental pollution. Environ Pollut 284:117391. https://doi.org/10.1016/j.envpol.2021.117391

Chantal L, Vanessa B, Steven M, Hugo J, François O, Peter S, Christine FP, Anthony CMM (2016) Physiological stress response of the scleractinian coral Stylophora pistillata exposed to polyethylene microplastics. 127469

Chapron L, Peru E, Engler A et al (2018) Macro- and microplastics affect cold-water corals growth, feeding and behaviour. Sci Rep. https://doi.org/10.1038/s41598-018-33683-6

Chen X, Chen X, Liu Q et al (2021) Used disposable face masks are significant sources of microplastics to environment. Environ Pollut. https://doi.org/10.1016/j.envpol.2021.117485

Cordova M, Hadi T, Prayudha B (2018) Occurrence and abundance of microplastics in coral reef sediment: a case study in Sekotong, Lombok-Indonesia. Adv Environ Sci 10:23-29. https://doi.org/ 10.5281/zenodo. 1297719

Cordova MR, Ulumuddin YI, Purbonegoro T, Shiomoto A (2021) Characterization of microplastics in mangrove sediment of Muara Angke Wildlife Reserve. Indonesia Mar Pollut Bull. https://doi.org/10.1016/j.marpolbul.2021.112012

Cormier B, Le Bihanic F, Cabar M et al (2021) Chronic feeding exposure to virgin and spiked microplastics disrupts essential biological functions in teleost fish. J Hazard Mater. https://doi.org/10. 1016/j.jhazmat.2021.125626

Costa CQV, Cruz J, Martins J et al (2021) Fluorescence sensing of microplastics on surfaces. Environ Chem Lett 19:1797-1802. https://doi.org/10.1007/s10311-020-01136-0

Covernton GA, Davies HL, Cox KD et al (2021) A Bayesian analysis of the factors determining microplastics ingestion in fishes. J Hazard Mater. https://doi.org/10.1016/j.jhazmat.2021.125405 
Daniel DB, Ashraf PM, Thomas SN, Thomson KT (2021) Microplastics in the edible tissues of shellfishes sold for human consumption. Chemosphere. https://doi.org/10.1016/j.chemosphere.2020. 128554

de Carvalho AR, Van-Craynest C, Riem-Galliano L et al (2021) Protocol for microplastic pollution monitoring in freshwater ecosystems: towards a high-throughput sample processing - microplastream. MethodsX. https://doi.org/10.1016/j.mex.2021.101396

de Smit JC, Anton A, Martin C et al (2021) Habitat-forming species trap microplastics into coastal sediment sinks. Sci Total Environ. https://doi.org/10.1016/j.scitotenv.2021.145520

de los Santos CB, Krång AS, Infantes E (2021) Microplastic retention by marine vegetated canopies: simulations with seagrass meadows in a hydraulic flume. Environ Pollut. https://doi.org/ 10.1016/j.envpol.2020.116050

Deng H, He J, Feng D et al (2021) Microplastics pollution in mangrove ecosystems: a critical review of current knowledge and future directions. Sci Total Environ. https://doi.org/10.1016/j.scitotenv. 2020.142041

Ewel KC, Twilley RR, Ong JE (1998) Different kinds of mangrove forests provide different goods and services. Glob Ecol Biogeogr Lett 7:83-94. https://doi.org/10.2307/2997700

Fendall LS, Sewell MA (2009) Contributing to marine pollution by washing your face: microplastics in facial cleansers. Mar Pollut Bull 58:1225-1228. https://doi.org/10.1016/j.marpolbul.2009. 04.025

Fischer M, Scholz-Böttcher BM (2017) Simultaneous trace identification and quantification of common types of microplastics in environmental samples by pyrolysis-gas chromatography-mass spectrometry. Environ Sci Technol 51:5052-5060. https://doi. org/10.1021/acs.est.6b06362

Ghosh A, Schmidt S, Fickert T, Nüsser M (2015) The Indian Sundarban mangrove forests: History, utilization, conservation strategies and local perception. Diversity 7:149-169. https://doi.org/10.3390/ d7020149

Grillo JF, Sabino MA, Ramos R (2021) Short-term ingestion and tissue incorporation of Polystyrene microplastic in the scleractinian coral Porites porites. Reg Stud Mar Sci. https://doi.org/10.1016/j. rsma.2021.101697

Guannel G, Arkema K, Ruggiero P, Verutes G (2016) The power of three: coral reefs, seagrasses and mangroves protect coastal regions and increase their resilience. PLoS ONE. https://doi. org/10.1371/journal.pone.0158094

Guimarães ATB, Charlie-Silva I, Malafaia G (2021) Toxic effects of naturally-aged microplastics on zebrafish juveniles: a more realistic approach to plastic pollution in freshwater ecosystems. $\mathbf{J}$ Hazard Mater. https://doi.org/10.1016/j.jhazmat.2020.124833

Gurjar UR, Xavier M, Nayak BB et al (2021) Microplastics in shrimps: a study from the trawling grounds of north eastern part of Arabian Sea. Environ Sci Pollut Res. https://doi.org/10.1007/ s11356-021-14121-z

Hankins C, Moso E, Lasseigne D (2021) Microplastics impair growth in two atlantic scleractinian coral species, Pseudodiploria clivosa and Acropora cervicornis. Environ Pollut. https://doi.org/10. 1016/j.envpol.2021.116649

Huang W, Chen M, Song B et al (2021) Microplastics in the coral reefs and their potential impacts on corals: a mini-review. Sci Total Environ. https://doi.org/10.1016/j.scitotenv.2020.143112

Hummel D, Fath A, Hofmann T, Hüffer T (2021) Additives and polymer composition influence the interaction of microplastics with xenobiotics. Environ Chem. https://doi.org/10.1071/EN21030

Ibrahim YS, Tuan Anuar S, Azmi AA et al (2021) Detection of microplastics in human colectomy specimens. JGH Open 5:116-121. https://doi.org/10.1002/jgh3.12457

Ibrahim-Bathis K (2021) Insight to the spatial-temporal extent of mangrove forests in the northern coast of Kerala. Remote
Sens Ocean Coast Environ. https://doi.org/10.1016/b978-012-819604-5.00021-4

Il KJ, An YJ (2021) Post COVID-19 pandemic: Biofragmentation and soil ecotoxicological effects of microplastics derived from face masks. J Hazard Mater. https://doi.org/10.1016/j.jhazmat. 2021.126169

Ivar Do Sul JA (2021) Why it is important to analyze the chemical composition of microplastics in environmental samples. Mar Pollut Bull. https://doi.org/10.1016/j.marpolbul.2021.112086

Ivar Do Sul JA, Costa MF (2014) The present and future of microplastic pollution in the marine environment. Environ Pollut 185:352-364. https://doi.org/10.1016/j.envpol.2013.10.036

Jambeck J, Lavender Law K, Geyer R (2017) Production, use and fate of all plastics ever made. Sci Adv III

Jawad LA, Adams NJ, Nieuwoudt MK (2021) Ingestion of microplastics and mesoplastics by Trachurus declivis (Jenyns, 1841) retrieved from the food of the Australasian gannet Morus serrator: First documented report from New Zealand. Mar Pollut Bull 170:112652. https://doi.org/10.1016/j.marpolbul.2021. 112652

Jensen LH, Motti CA, Garm AL et al (2019) Sources, distribution and fate of microfibres on the Great Barrier Reef, Australia. Sci Rep. https://doi.org/10.1038/s41598-019-45340-7

Jeyavani J, Sibiya A, Shanthini S et al (2021) A review on aquatic impacts of microplastics and its bioremediation aspects. Curr Pollut Reports. https://doi.org/10.1007/s40726-021-00188-2

Jia T, Wu Z, Cai W et al (2021) Differential enrichment and physiological impacts of ingested microplastics in scleractinian corals in situ. J Hazard Mater 404:124205

José GBD (2002) The pollution of the marine environment by plastic debris: a review. Mar Pollut Bull 44:842-852

Jung JW, Park JW, Eo S et al (2021) Ecological risk assessment of microplastics in coastal, shelf, and deep sea waters with a consideration of environmentally relevant size and shape. Environ Pollut. https://doi.org/10.1016/j.envpol.2020.116217

Karami A, Golieskardi A, Bin HY et al (2017) Microplastics in eviscerated flesh and excised organs of dried fish. Sci Rep. https://doi. org/10.1038/s41598-017-05828-6

Karbalaei S, Golieskardi A, Hamzah HB et al (2019) Abundance and characteristics of microplastics in commercial marine fish from Malaysia. Mar Pollut Bull 148:5-15. https://doi.org/10.1016/j. marpolbul.2019.07.072

Kokalj AJ, Dolar A, Titova J et al (2021) Long term exposure to virgin and recycled ldpe microplastics induced minor effects in the freshwater and terrestrial crustaceans daphnia magna and porcellio scaber. Polymers 13:1-17. https://doi.org/10.3390/polym 13050771

Kumkar P, Gosavi SM, Verma CR et al (2021) Big eyes can't see microplastics: feeding selectivity and eco-morphological adaptations in oral cavity affect microplastic uptake in mud-dwelling amphibious mudskipper fish. Sci Total Environ. https://doi.org/ 10.1016/j.scitotenv.2021.147445

Lamb JB, Willis BL, Fiorenza EA et al (2018) Plastic waste associated with disease on coral reefs. Science 359:460-462. https://doi.org/ 10.1126/science.aar3320

Lee A, Mondon J, Merenda A et al (2021) Surface adsorption of metallic species onto microplastics with long-term exposure to the natural marine environment. Sci Total Environ. https://doi.org/ 10.1016/j.scitotenv.2021.146613

Liao B, Wang J, Xiao B et al (2021) Effects of acute microplastic exposure on physiological parameters in Tubastrea aurea corals. Mar Pollut Bull. https://doi.org/10.1016/j.marpolbul.2021.112173

Luo W, Su L, Craig NJ et al (2019) Comparison of microplastic pollution in different water bodies from urban creeks to coastal waters. Environ Pollut 246:174-182. https://doi.org/10.1016/j. envpol.2018.11.081 
Lv L, Yan X, Feng L et al (2021) Challenge for the detection of microplastics in the environment. Water Environ Res 93:5-15. https:// doi.org/10.1002/wer.1281

Ma H, Pu S, Liu S et al (2020) Microplastics in aquatic environments: toxicity to trigger ecological consequences. Environ Pollut. https://doi.org/10.1016/j.envpol.2020.114089

Maghsodian Z, Sanati AM, Ramavandi B et al (2021) Microplastics accumulation in sediments and Periophthalmus waltoni fish, mangrove forests in southern Iran. Chemosphere. https://doi. org/10.1016/j.chemosphere.2020.128543

Martin C, Almahasheer H, Duarte CM (2019) Mangrove forests as traps for marine litter. Environ Pollut 247:499-508. https://doi. org/10.1016/j.envpol.2019.01.067

Mendrik FM, Henry TB, Burdett $\mathrm{H}$ et al (2021) Species-specific impact of microplastics on coral physiology. Environ Pollut. https://doi. org/10.1016/j.envpol.2020.116238

Nigamatzyanova L, Fakhrullin R (2021) Dark-field hyperspectral microscopy for label-free microplastics and nanoplastics detection and identification in vivo: a Caenorhabditis elegans study. Environ Pollut. https://doi.org/10.1016/j.envpol.2020.116337

Padervand M, Lichtfouse E, Robert D, Wang C (2020) Removal of microplastics from the environment: a review. Environ Chem Lett 18:807-828. https://doi.org/10.1007/s10311-020-00983-1

Palacios-Mateo C, van der Meer Y, Seide G (2021) Analysis of the polyester clothing value chain to identify key intervention points for sustainability. Environ Sci Eur. https://doi.org/10.1186/ s12302-020-00447-x

Patrício Silva AL, Prata JC, Mouneyrac C et al (2021) Risks of Covid19 face masks to wildlife: present and future research needs. Sci Total Environ 792:148505. https://doi.org/10.1016/j.scitotenv. 2021.148505

Qiao R, Deng Y, Zhang S et al (2019) Accumulation of different shapes of microplastics initiates intestinal injury and gut microbiota dysbiosis in the gut of zebrafish. Chemosphere. https://doi.org/10. 1016/j.chemosphere.2019.07.065

Ragavan P, Dubey SK, Dagar JC et al (2019) Current understanding of the Mangrove forests of India. Res Dev Saline Agric. https://doi. org/10.1007/978-981-13-5832-6_8

Ragusa A, Svelato A, Santacroce C et al (2021) Plasticenta: first evidence of microplastics in human placenta. Environ Int. https:// doi.org/10.1016/j.envint.2020.106274

Razeghi N, Hamidian AH, Wu C et al (2021) Microplastic sampling techniques in freshwaters and sediments: a review. Environ Chem Lett. https://doi.org/10.1007/s10311-021-01227-6

Reichert J, Schellenberg J, Schubert P, Wilke T (2018) Responses of reef building corals to microplastic exposure. Environ Pollut 237:955-960. https://doi.org/10.1016/j.envpol.2017.11.006

Reichert J, Arnold AL, Hoogenboom MO et al (2019) Impacts of microplastics on growth and health of hermatypic corals are species-specific. Environ Pollut. https://doi.org/10.1016/j.envpol. 2019.113074

Sankoda K, Yamada Y (2021) Occurrence, distribution, and possible sources of microplastics in the surface river water in the Arakawa River watershed. Environ Sci Pollut Res 28:27474-27480. https://doi.org/10.1007/s11356-021-12459-y

Santana MFM, Dawson AL, Motti CA et al (2021) Ingestion and depuration of microplastics by a planktivorous coral reef fish. Pomacentrus Amboinensis Front Environ Sci. https://doi.org/10.3389/ fenvs.2021.641135

Sasidhar (2020) Mangrove medicinal plants and its chemistry: a review. Int Multidiscip Edu Res

Schmidt C, Krauth T, Wagner S (2017) Export of plastic Debris by Rivers into the Sea. Environ Sci Technol 51:12246-12253. https:// doi.org/10.1021/acs.est.7b02368

Sevwandi Dharmadasa WLS, Andrady AL, Kumara PBTP et al (2021) Microplastics pollution in Marine protected areas of
Southern Sri Lanka. Mar Pollut Bull. https://doi.org/10.1016/j. marpolbul.2021.112462

Silva AB, Bastos AS, Justino CIL et al (2018) Microplastics in the environment: challenges in analytical chemistry-a review. Anal Chim Acta 1017:1-19. https://doi.org/10.1016/j.aca. 2018.02.043

Small C, Nicholls RJ (2003) A global analysis of human settlement in coastal zones. J Coast Res 584-599

Soares MO, Rossi S, Gurgel AR et al (2021) Impacts of a changing environment on marginal coral reefs in the Tropical Southwestern Atlantic. Ocean Coast Manag. https://doi.org/10.1016/j.oceco aman.2021.105692

Spadaro AJ, Butler MJ (2021) Herbivorous crabs reverse the seaweed dilemma on coral reefs. Curr Biol 31:853-859.e3. https://doi.org/ 10.1016/j.cub.2020.10.097

Tan F, Yang H, Xu X et al (2020) Microplastic pollution around remote uninhabited coral reefs of Nansha Islands, South China Sea. Sci Total Environ. https://doi.org/10.1016/j.scitotenv.2020.138383

Tebbett SB, Bellwood DR (2021) Algal turf productivity on coral reefs: a meta-analysis. Mar Environ Res. https://doi.org/10.1016/j. marenvres.2021.105311

Thompson RC, Ylva O, Richard PM et al (2004) Lost at sea: where is all the plastic? Science 80(304):838

Umamaheswari S, Priyadarshinee S, Bhattacharjee M et al (2020) Exposure to polystyrene microplastics induced gene modulated biological responses in zebrafish (Danio rerio). Chemosphere. https://doi.org/10.1016/j.chemosphere.2020.128592

Unsworth RKF, Higgs A, Walter B et al (2021) Canopy accumulation: are seagrass meadows a sink of microplastics? Oceans 2:162178. https://doi.org/10.3390/oceans 2010010

Urbina-Barreto I, Chiroleu F, Pinel R et al (2021) Quantifying the shelter capacity of coral reefs using photogrammetric 3D modeling: from colonies to reefscapes. Ecol Indic. https://doi.org/10.1016/j. ecolind.2020.107151

Utami DA, Reuning L, Konechnaya O, Schwarzbauer J (2021) Microplastics as a sedimentary component in reef systems: a case study from the Java Sea. Sedimentology. https://doi.org/10.1111/sed. 12879

Van Cauwenberghe L, Vanreusel A, Mees J, Janssen CR (2013) Microplastic pollution in deep-sea sediments. Environ Pollut 182:495499. https://doi.org/10.1016/j.envpol.2013.08.013

Vidyasakar A, Neelavannan K, Krishnakumar S et al (2018) Macrodebris and microplastic distribution in the beaches of Rameswaram Coral Island, Gulf of Mannar, Southeast coast of India: a first report. Mar Pollut Bull 137:610-616. https://doi.org/10.1016/j. marpolbul.2018.11.007

Wang YS, Gu JD (2021) Ecological responses, adaptation and mechanisms of mangrove wetland ecosystem to global climate change and anthropogenic activities. Int Biodeterior Biodegrad. https:// doi.org/10.1016/j.ibiod.2021.105248

Wang Z, An C, Chen X et al (2021) Disposable masks release microplastics to the aqueous environment with exacerbation by natural weathering. J Hazard Mater. https://doi.org/10.1016/j.jhazmat. 2021.126036

Weber A, Jeckel N, Weil C et al (2021) Ingestion and toxicity of polystyrene microplastics in freshwater bivalves. Environ Toxicol Chem. https://doi.org/10.1002/etc.5076

Xie H, Chen J, Feng L et al (2021) Chemotaxis-selective colonization of mangrove rhizosphere microbes on nine different microplastics. Sci Total Environ. https://doi.org/10.1016/j.scitotenv.2020. 142223

Yin L, Wen X, Huang D et al (2021) Microplastics retention by reeds in freshwater environment. Sci Total Environ. https://doi.org/10. 1016/j.scitotenv.2021.148200

Yudha RP, Sugito YS, Sillanpää M, Nurvianto S (2021) Impact of logging on the biodiversity and composition of flora and fauna in the 
mangrove forests of Bintuni Bay, West Papua, Indonesia. Ecol Manag. https://doi.org/10.1016/j.foreco.2021.119038

Zamprogno GC, Caniçali FB, dos Cozer CR et al (2021) Spatial distribution of microplastics in the superficial sediment of a mangrove in Southeast Brazil: a comparison between fringe and basin. Sci Total Environ. https://doi.org/10.1016/j.scitotenv.2021.146963

Zhang L, Zhang S, Wang Y et al (2019) The spatial distribution of microplastic in the sands of a coral reef island in the South China Sea: comparisons of the fringing reef and atoll. Sci Total Environ 688:780-786. https://doi.org/10.1016/j.scitotenv.2019.06.178

Zhang L, Zhang S, Guo J et al (2020) Dynamic distribution of microplastics in mangrove sediments in Beibu Gulf, South China: implications of tidal current velocity and tidal range. J Hazard Mater. https://doi.org/10.1016/j.jhazmat.2020.122849
Zhang X, Wen K, Ding D et al (2021) Size-dependent adverse effects of microplastics on intestinal microbiota and metabolic homeostasis in the marine medaka (Oryzias melastigma). Environ Int. https:// doi.org/10.1016/j.envint.2021.106452

Zhu C, Kanaya Y, Tsuchiya M et al (2021) Optimization of a hyperspectral imaging system for rapid detection of microplastics down to $100 \mu \mathrm{m}$. MethodsX. https://doi.org/10.1016/j.mex.2020. 101175

Publisher's Note Springer Nature remains neutral with regard to jurisdictional claims in published maps and institutional affiliations. 